University of Nebraska - Lincoln

DigitalCommons@University of Nebraska - Lincoln

Faculty Publications from Nebraska Center for

Materials and Nanoscience

Materials and Nanoscience, Nebraska Center

for $(\mathrm{NCMN})$

2007

\title{
Quantitative Analysis of Polycrystalline Electron Diffraction \\ Patterns
}

Xingzhong Li

University of Nebraska-Lincoln, xli2@unl.edu

Follow this and additional works at: https://digitalcommons.unl.edu/cmrafacpub

Part of the Nanoscience and Nanotechnology Commons

Li, Xingzhong, "Quantitative Analysis of Polycrystalline Electron Diffraction Patterns" (2007). Faculty Publications from Nebraska Center for Materials and Nanoscience. 95.

https://digitalcommons.unl.edu/cmrafacpub/95

This Article is brought to you for free and open access by the Materials and Nanoscience, Nebraska Center for (NCMN) at DigitalCommons@University of Nebraska - Lincoln. It has been accepted for inclusion in Faculty Publications from Nebraska Center for Materials and Nanoscience by an authorized administrator of DigitalCommons@University of Nebraska - Lincoln. 


\title{
Quantitative Analysis of Polycrystalline Electron Diffraction Patterns
}

\author{
X.Z. Li
}

Nebraska Center for Materials and Nanoscience, University of Nebraska, Lincoln, NE 68588

Image processing and computer-assisted analysis are very important in electron microscopy/crystallography, e.g., computer programs have been well developed for image processing and simulation for high-resolution electron microscopy images, and are widely used in research. Unfortunately, few computer programs have been developed for analysis and processing electron diffraction ring patterns. Facing this situation, Labar [1] developed ProcessDiffraction, a computer program to process electron diffraction patterns from polycrystalline and amorphous samples, with an aim to provides good angular resolution, quantified intensities, and reproducible identification of discontinuous and/or faint rings. For phase identification, it is to compare the generated diffractogram to the X-ray diffraction data bases. Li [2] developed JECP/PCED, a computer program for simulation of polycrystalline electron diffraction pattern and phase identification, which uses the raw or processed diffraction pattern as the input file and directly match to the simulated ring pattern. Both of the programs have proved to be fast yet accurate for phase identification.

The goal of quantitative analysis of polycrystalline electron diffraction patterns is to precisely determine peak positions (d-spacing), shapes (full-width at half-maximum) and integrated intensities or the net peak heights for roughly estimated intensities. In the present work, we designed a computer program (PROJECT/QPCED) with this goal, which has been implemented in Java. [3] Figure 1. shows the graphic user interface of PROJECT/QPCED together with a diffraction pattern of the (001)-orientated $\mathrm{ZnO}$ film as example..

The main steps in the analysis procedure are, (a) to find the center of the diffraction ring pattern, (b) sum up or average the intensities over the rings, and (c) find the peak positions, shapes and integrated intensities. In comparison with ProcessDiffraction and its later version, different ways to perform the operations have been adopted in QPCED, some examples are listed here.

(i) To find the center of a diffraction ring pattern, the image (diffraction pattern) is shifted referring to an adjustable ring mark with a fixed center. In ProcessDiffraction, a computer algorithm is used for final adjustment when averaged intensities are measured. In QPCED, the overall intensity distribution in both of the horizontal $(\mathrm{X})$ and vertical (Y) scan-line intensity profiles is visually cross-checked for the determination of the center.

(ii) To check and correct the ellipticity, the ring mark is adjusted to overlap a selected diffraction ring. In ProcessDiffraction, a reference ellipse is defined, averages the intensities of the ring over the ellipse. In QPCED, the image processing is carried out to correct the ellipticity, and then the intensities of the modified circular ring sum up.

(iii) In ProcessDiffraction, averaged intensities over each ring are used to show the intensity profile of the intensity distribution, and half circles are drawn on one side of the original diffraction pattern to highlight the diffraction rings. In QPCED the sum of intensities over each ring is used to show the 
intensity profile, and a processed image with averaged intensity for each diffraction ring is generated to improve the visibility of the original diffraction pattern. The processed image can be used for phase identification using JECP/PCED.

\section{References}

[1] Janos L. Labar, EUREM 12 (2000) 1379.

[2] X.Z. Li, Ultramicroscopy 99 (2004) 257.

[3] X.Z. Li, program specification and a demo in http://www.unl.edu/CMRAcfem/XZLI/programs.

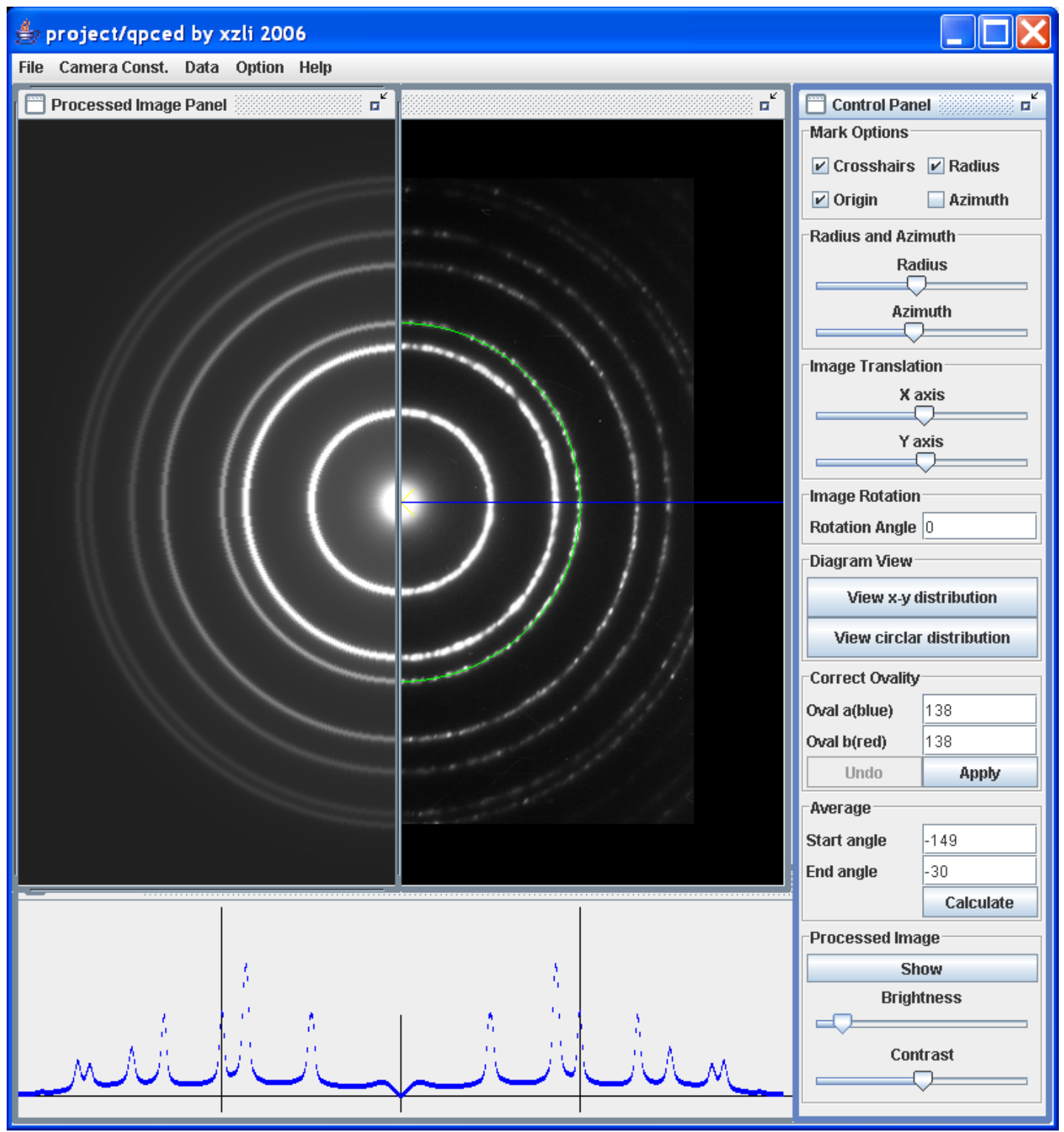

Figure 1. Graphic user interface of PROJECT/QPCED. Operations are shown on the right panel. Processed and experimental diffraction patterns of a (001)-orientated $\mathrm{ZnO}$ film are shown in left and right sides in the main panel. Intensity profile is shown on the lower panel, where the height of the incident beam is cut off due to the serious saturation of intensity. 